\title{
Water mites of the genus Torrenticola Piersig (Acari: Hydrachnidia, Torrenticolidae) from Iran
}

\author{
V. Pesic ${ }^{1 *}$, A. Saboori², M. Asadi ${ }^{2}$ \\ ${ }^{1}$ Department of Biology, Faculty of Sciences, University of Crna Gora, Cetinjski put b.b., 81000 Podgorica, Montenegro, Serbia and Montenegro \\ ${ }^{2}$ Department of Plant Protection, College of Agriculture, University of Tehran, Karaj, Iran
}

Five water mite species of the genus Torrenticola Piersig (Acari: Hydrachnidia, Torrenticolidae) are reported from Iran. T. disabatinola and T. persica are described as new to science; first description are given of the female of T. saboorii Pesic \& Asadi, 2002; new records are given for T. nana Di Sabatino \& Gerecke, 2003, and T. cf. jasminae Bader, 1988.

Keywords : Acari, Iran, Torrenticola, taxonomy, running waters.

\section{Introduction}

At present, six species of the genus Torrenticola Piersig are known from Iran (Bader 1988, Bader \& Sepasgozarian, 1987, Pesic \& Asadi 2002, Asadi et al. 2003): Torrenticola baueri Bader \& Sepasgozarian, 1987, Torrenticola saboorii Pesic \& Asadi, 2002, Torrenticola nana Di Sabatino \& Gerecke, 2003, Torrenticola jasminae Bader 1988, Torrenticola ramini Bader, 1988, and Torrenticola wiljae Bader, 1988. During a survey of the freshwater fauna of Iran, several species of the water mite genus Torrenticola Piersig were collected, including a two new species. The aim of this paper is to contribute elements for an extended revision of the diversity, distribution and ecology of torrenticolid water mites in the Middle East area.

\section{Material and Methods}

Water mites were collected by hand netting, sorted on the spot from the living material, conserved in Koenike's fluid and dissected as described elsewhere (e.g. Gerecke 1991). Slide-mounted specimens and material preserved in fluid is lodged in the collection of the

\footnotetext{
* Corresponding author : E-mail : pesic@cg.yu
}

first author. The holotypes and paratypes of the new species are deposited in the Museum of the Natural History of Podgorica (Crna Gora), further paratypes will be deposited in the zoological museum, College of Agriculture of Tehran University in Karaj (Iran). In the section «New records » collecting site abbreviations derive from the geographical database Pesic.

The composition of the material is given as: (males/females/deutonymphs), and the following abbreviations are used: I-L-6 = Leg 1, sixth segment, P-1 = palp, first segment, $\mathrm{Cx}-1$ = first coxae, $\mathrm{L}=$ length, $\mathrm{W}$ = width, $\mathrm{H}=$ height, $\mathrm{n}=$ number of specimens examined. All measurements are given in $(\mathrm{m}$.

\section{Results}

Genus Torrenticola Piersig, 1896

Subgenus Torrenticola Piersig, 1896

Torrenticola disabatinola Pesic sp. nov.

(Fig. 1A-E)

Type material: Holotype: female, dissected and slide mounted in Hoyer's fluid. Iran: IR6 Mazandaran Province, Elburs Mt., the hygropetric stream near Kandelous (on Kojor road), $\mathrm{T}=14^{0}, 2000 \mathrm{~m}$ asl., 18.07.2003, leg. Pesic, Asadi, Saboori \& Akrami. Paratypes: one female, same data as holotype, dissected and slide mounted in Hoyer's fluid. 
Diagnosis: Females: median suture of $\mathrm{Cx}-2+3$ completely reduced, gnathosoma with strongly dorsally curved and upturned rostrum, genital field large, P-4 lacking a mediodistal peg-like seta.

Description: Female (measurements of paratype are given in parentheses): Idiosoma (Fig. 1B) L 867 (858), W 750 (742), dorsal shield (Fig. 1A) L 794 (754), W 563 (566), L/W ratio 1.41 (1.33); dorsal plate L 754 (717); shoulder plate L/W 213/88 (227/92), L/W ratio 2.42 (2.47); frontal plate L/W 150/71 (146/67), L/W ratio 2.1 (2.2); shoulder/frontal plate $\mathrm{L}$ ratio 1.42 (1.55); gnathosomal bay L 204 (200), Cx-1 L 348 (333), median L 142 (133), Cx-2+3 not in touch medially; genital field large and pentagon-shaped, 213 (204) in length, 192 (186) in width, L/W ratio 1.1 (1.1); distance genital field-excretory pore 244 (233), genital field-caudal body margin 325 (333); gnathosoma (Fig. 1C) ventral L 450 (435), distally with strongly dorsally curved and upturned rostrum; chelicera (Fig. 1E) L 486 (504), L/H ratio (8.69), cheliceral claw L 110 (114), basal segment/claw L ratio 3.83 (3.69); palp (Fig. 1C,D) total L 459 (476) dorsal length of palp segments: P-1 54 (60), P-2 154 (159), P-3 77 (80), P-4 147 (142), P-5 27 (26); relative length (in parentheses $\%$ of total length) of palp segments: P-1 11.8 (12.8), P233.6 (34.0), P-3 16.8 (17.1), P-4 32.0 (30.4), P-5 5.9 (5.6) $\mathrm{P}-2 / \mathrm{P}-4$ ratio 1.05 (1.12); $\mathrm{P}-4$ lacking a mediodistal peg-like seta, ventral protuberances forming unique tip bearing one long and two short hairs.

Male: unknown

Discussion: T. disabatinola sp. nov. differs from all other species of the subgenus Torrenticola, in the combination of dorsally strongly curved and upturned gnathosomal rostrum, a completely reduced median suture of $\mathrm{Cx}-2+3$, and a P-4 lacking a mediodistal peg-like seta.

Etymology: The species is named after Dr. Antonio Di Sabatino (L'Aquila, Italy), in appreciation of his studies concerning the Torrenticola species.

Distribution: Iran; only known from the locus typicus.

\section{Torrenticola saboorii Pesic \& Asadi, 2002}

(Fig. 2A-C)

Material examined: Iran: IR16 Kerman Province, stream in village Sirch, $50 \mathrm{~km}$ E from Kerman (ca. 30.12N 57.33E), 24.07.2003, leg. Pesic (1/0/0); IR23 Kerman Province, ca. 60 km SW Kerman, SW Bardsir, Bid Khan stream near Bid Khan village (ca. 29.50N 56.24E), 26.07.2003, leg. Pesic (6/29/0); IR24 Kerman Province, stream in Simk village, 27.07.2003, leg. Pesic (7/7/0); IR25 Kerman Province, Vamegh Abad stream near Vamegh Abad village, 27.07.2003, leg. Pesic (5/13/0); IR31 Chahar Mahal and Bakhtiari Province, Omid Abad stream near Eisa Abad (After Fill Abad to Kuhrang), 01.08.2003, leg. Pesic (12/6/0).

Description. Females (based on two specimens from IR23): Idiosoma (Fig. 2B) L 867-950, W 667-717, dorsal shield (Fig. 2A) L 726-821, W 454-500, L/W ratio 1.45-1.8; dorsal plate L 692-771; shoulder plate L/W 220-233/83-92, L/W ratio 2.53-2.65; frontal plate L/W 142-154/60-71, L/W ratio 2.2-2.37; shoulder/frontal plate L ratio 1.51-1.55; gnathosomal bay L 163-175, Cx-1 L 332-363, median L 167-188, Cx-2+3 median L 38-42; ratio Cx-1 L/Cx-2+3 median L 7.9-9.6, Cx-1 median L/Cx-2+3 median L 3.98-4.95; genital field (Fig. 2B) L/W 179-188/176-185, L/W ratio 1.02; distance genital field-excretory pore 225-263, genital field-caudal body margin 329-375; gnathosoma (Fig. 2C) ventral L 333-360; chelicera L 379-413, basal segment/claw L ratio 5.2-5.7; palp (Fig. 2C) total L 342-368, dorsal length and relative length (in parentheses \% of total length) of palp segments: P-1 37-40 (10.8-10.9), P-2 108-119 (31.6-32.3), P-3 66-71 (19.3), P-4 110-115 (31.3-32.2), P-5 21-23 (6.1-6.3); $\mathrm{P}-2 / \mathrm{P}-4$ ratio $0.98-1.03$; ventral protuberances on $\mathrm{P}-4$ forming unique tip bearing one long and two short hairs.

Remarks: This is the second record of the species after the orginal description, and the first discovery of the female. Males of this species are characterized by the considerably extended ventral plate, by a long suture line of $\mathrm{Cx}-2+3(183-196, \mathrm{n}=5)$ and a medium sized genital field (L/W 140-158/105-113, n=5).

Distribution: Iran.

\section{Torrenticola nana Di Sabatino \& Gerecke, 2003}

Material examined: Iran: IR43 Fars Province, Tang Boragh stream, $2 \mathrm{~km}$ from Tang Boragh village (near Eghlid city), 06.08.2003, leg. Pesic (0/2/0)

Records from the study area: Kohpaye stream (Kerman Province) - Asadi et al. (2003).

Distribution: Iran, Israel.

Subgenus Megapalpis Halbert, 1944

Torrenticola persica Pesic sp. nov.

(Fig. 3A-E)

Type material: Holotype: female, dissected and slide mounted in Hoyer's fluid. Iran: IR47 Tehran Province, Sijan stream in Sijan village (under Dareh Bridge), 14.08.2003, leg. Pesic \& Saboori.

Diagnosis: Female: Idiosoma elongated (dorsal shield L/W ratio 1.6), relatively short cheliceral claw (basal segment/claw L ratio 5.66), P-2 lacking a ven- 

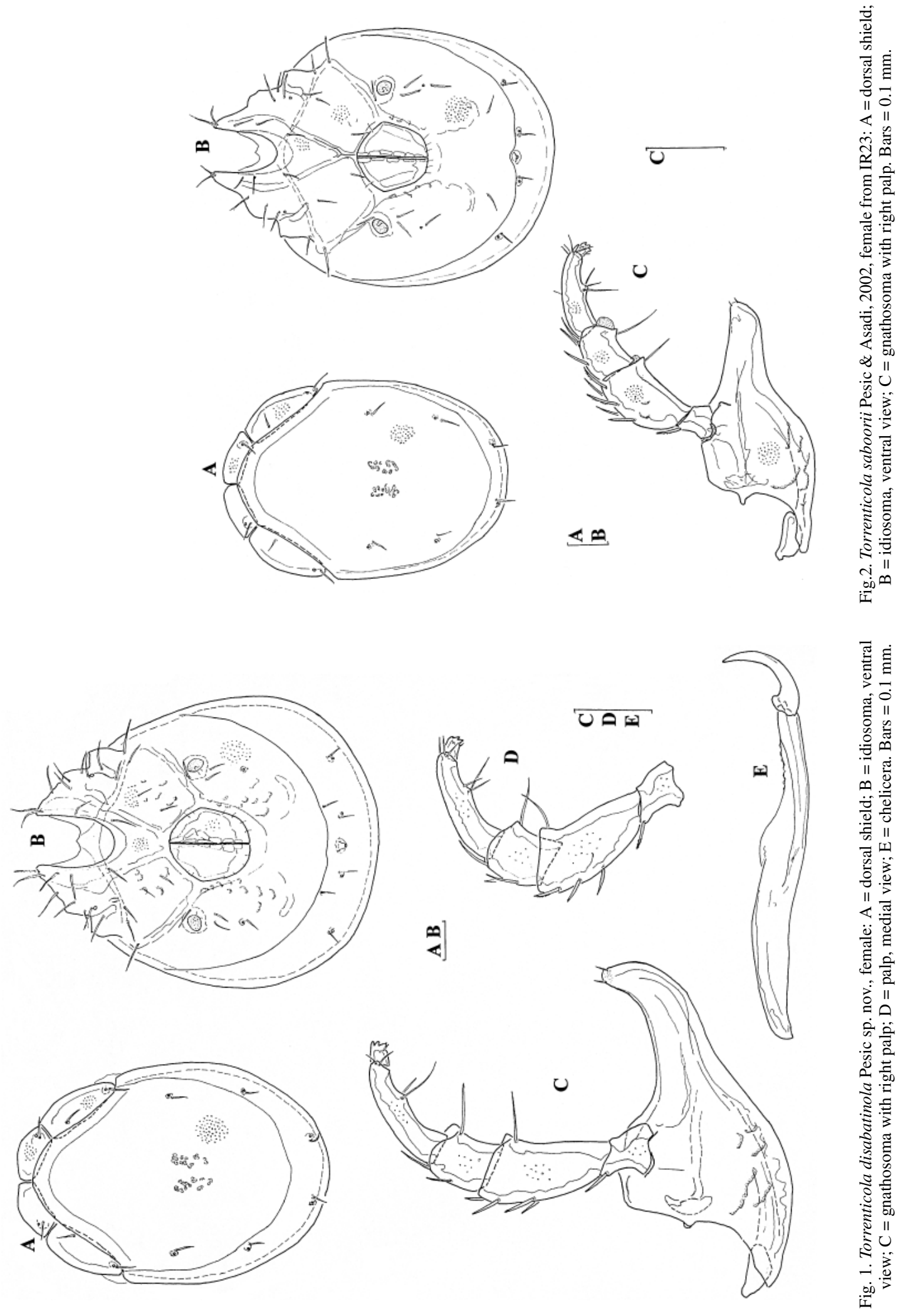
tral tubercle, excretory pore fused with the area of primary sclerotization.

Description: Female: Idiosoma (Fig. 3B) L 878, W 575, dorsal shield (Fig. 3A) L 758, W 475, L/W ratio 1.6; dorsal plate L 708; shoulder plate L/W 204/67, $\mathrm{L} / \mathrm{W}$ ratio 3.04; frontal plate $\mathrm{L} / \mathrm{W} 139 / 69$, L/W ratio 2.01; shoulder/frontal plate L ratio 1.47; gnathosomal bay L 156, Cx-1 L 292, median L 133, Cx-2+3 median L 58; ratio $\mathrm{Cx}-1 \mathrm{~L} / \mathrm{Cx}-2+3$ median L 5.03, Cx-1 median L/Cx-2+3 median L 2.3; genital field L/W 183/166, L/W ratio 1.1; distance genital field-excretory pore 244 , genital field-caudal body margin 367 ; excretory pore fused with the area of primary sclerotization; gnathosoma (Fig. 3D) with a long, dorsally curved rostrum, ventral L 388; chelicera (Fig. 3E) L 408, $\mathrm{L} / \mathrm{H}$ ratio 20.8 , basal segment/claw $\mathrm{L}$ ratio 5.66; palp (Fig. 3C, D) total L 371, dorsal length and relative length (in parentheses \% of total length) of palp segments: P-1 59 (15.9), P-2 144 (38.8), P-3 58 (15.6), P487 (23.5), P-53 23 (6.2); P-2/P-4 ratio 1.65.

Male: unknown.

Discussion : T. persica sp. nov. can be easily distinguished from all other Palaearctic species of the subgenus Megapalpis, on the basis of a excretory pore fused with the area of primary sclerotization. T. persica sp. nov. differs from T. thori Halbert, 1944 in a much less developed cheliceral claw. T. persica sp. nov. differs from the three additional Palaearctic species of the subgenus Megapalpis lacking a ventral tubercle on P-2 (T. tenuirostris Viets, 1936, T. fagei E. Angelier, 1949 and T. remyi E. Angelier, 1949), in the combination of an elongated idiosoma, a relatively short cheliceral claw, and a different ratio P-2/P-4 (see : Di Sabatino et al. 2003).

Etymology: The species is named for its occurrence in Iran (Persia).

Distribution: Iran; only known from the locus typicus.

\section{Torrenticola cf. jasminae Bader, 1988}

(Fig. A-D)

Material examined: Iran: IR25 Kerman Province, Vamegh Abad stream near Vamegh Abad village, 27.07.2003, leg. Pesic (0/1/0).

Description: Female: Idiosoma (Fig. 4B) L 803, W 583, dorsal shield (Fig. 4A) L 708, W 442; dorsal plate L 667 (L/W ratio 1.51); shoulder plate L/W 193/67, $\mathrm{L} / \mathrm{W}$ ratio 2.9; frontal plate $\mathrm{L} / \mathrm{W} 138 / 58, \mathrm{~L} / \mathrm{W}$ ratio 2.3; shoulder/frontal plate $\mathrm{L}$ ratio 1.4; gnathosomal bay $\mathrm{L}$ 146, Cx-1 L 279, median L 133, Cx-2+3 median L 58; ratio $\mathrm{Cx}-1 \mathrm{~L} / \mathrm{Cx}-2+3$ median $\mathrm{L} 4.8, \mathrm{Cx}-1$ median
L/Cx-2+3 median L 2.3; genital field (Fig. 4B) L/W $171 / 150, \mathrm{~L} / \mathrm{W}$ ratio 1.1 ; distance genital field-excretory pore 221, genital field-caudal body margin 317 ; gnathosoma (Fig. 4C) ventral L413; chelicera (Fig. 4D) L 436, cheliceral basal segment L 398, cheliceral claw L 67, H 25 (basal segment/claw L ratio 5.96, L/H ratio 17.4); palp (Fig. 4C) total L 404, dorsal length and relative length (in parentheses $\%$ of total length) of palp segments: P-1 64 (15.8), P-2 154 (38.1), P-3 63 (15.6), P-4 94 (23.3), P-5 29 (7.2); P-2/P-4 ratio 1.64; ventral seta of $\mathrm{P}-2$ inserted on a well developed ventral projection.

Remarks: After the original description from the Elburs Mt. (Bader 1988), based on a single male, only one further record of T. jasminae has been published from Israel (Di Sabatino et al. 2003) based on a single female. Our female differs from specimens from Israel which are suspected to represent the female sex of $T$. jasminae (in parentheses [from Di Sabatino et al. 2003]) due to a relatively longer cheliceral claw with a 5.96 (6.5) basal segment/claw ratio and a $\mathrm{L}$ ratio $\mathrm{P}$ 2/P-4 of 1.64 (1.9). For the time being they all should be considered as representants of $T$. jasminae, in this concept a species with a considerable variability range. However, the attribution of the populations from Israel and Kerman Province to the species should be verified by studies on male specimens from these populations and females from the Elburs Mountain.

Distribution: Iran, Israel.

\section{Acknowledgements}

We are very thankful to M.Sc. Mohammad Ali Akrami (Abarkuh), M.Sc. Mojtaba Hosseini (Yazd), Miss. M.Sc. Malihe Latify (Kerman), Mahdi Jalaeian (Isfahan) and Morteza Asadi (Kerman) for the help in collecting some specimens considered in this study. Further, we are very thankful to Dr. Antonio Di Sabatino (L'Aquila, Italy) for critically reading a former draft of this paper. The first author is very thankful to Dr. Reinhard Gerecke (Tübingen, Germany) for useful and friendly advice during the studies of the Iranian water mites. The project on which this paper was based was partly supported by a grant from «Center of Excellence of Plant Protection », Department of Plant Protection, College of Agriculture, Tehran University, Karaj, Iran.

\section{References}

Asadi, M., Pesic, V. \& Saboori, A. 2003. - Two interesting water mite species (Acari, Hydrachnidia) from Iran, with redescription of the female of Atractides cf. arcuatus Thor, 1914. Zool. Mid. East, 30, 95-100.

Bader, C. 1988. - Die Torrenticolidae (Acari,Hydrachnellae). Eine abklärende Studie, ber eine schw ierige Wassermilben-Familie. Rev. Suisse Zool., 95, 87-98.

Bader, C. \& Sepasgozarian, H. 1987. - Wassermilben aus dem Iran (Acari, Prostigmata, Hydrachnellae): 17. Torrenticola baueri, nov. spec. Internat. J. Acarol., 13, 183-188. 

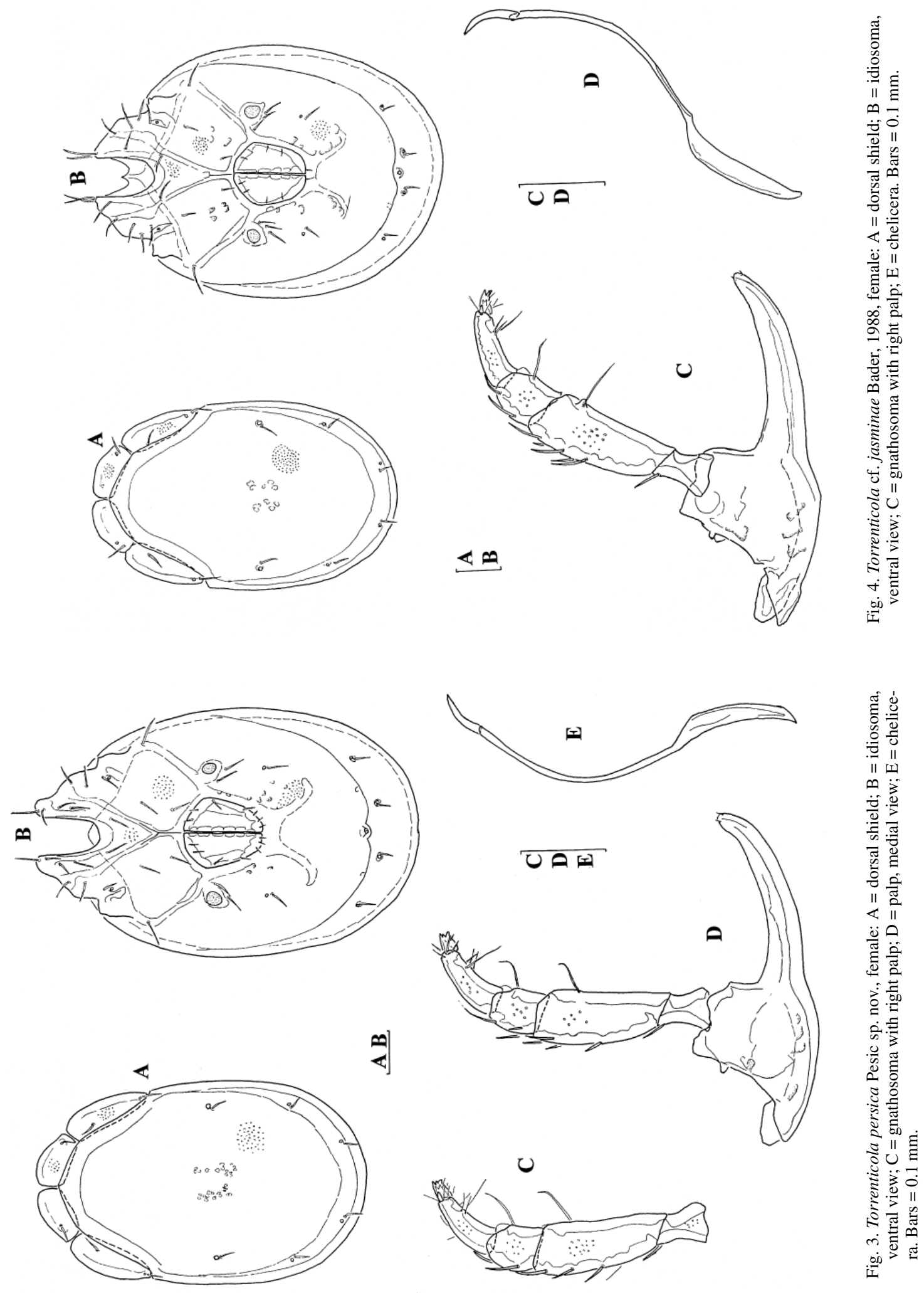

॥

离宫

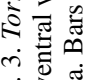


Di Sabatino, A., Gerecke, R., Smit, H., Pesic, V., \& Panesar, A. 2003. - Water mites of the family Torrenticolidae (Acari, Actinedida, Hydrachnidia) from the Eastern Mediterranean region. $\mathrm{Ar}$ chiv Hydrobiol. Suppl., 139, 1-39.

Gerecke, R. 1991. - Taxonomische, faunistische und ökologische Untersuchungen an Wassermilben (Acari, Actinedida) aus Sizilien unter Berücksichtigung anderer aquatischer Invertebraten. Lauterbornia, 7, 1-304.
Pesic, V. \& Asadi, M. 2002. - Two new water mite species from Iran of the water mite families Torrenticolidae and Hygrobatidae (Acari: Hydrachnidia). Zootaxa, 127, 1-7.

Wiles, P.R. 1997. - Asian and Oriental Torrenticolidae Piersig, 1902 (Acari: Hydrachnidia: Lebertioidea): a revision of the family and description of new species of Torrenticola Piersig and Pseudotorrenticola Walter, from Southeast Asia. J. Nat. Hist., 31, 191-236. 